MATEC Web of Conferences 25, 04011 (2015)

DOI: $10.1051 /$ matecconf/ 20152504011

(C) Owned by the authors, published by EDP Sciences, 2015

\title{
The Process Selection and Design for the Second Phase Project of the Guanjinggang Water Plant
}

\author{
Jiajiong Xu \\ School of Municipal and Environmental Engineering, Harbin Institute of Technology, Harbin, Heilongjiang, \\ China \\ Shanghai Municipal Engineering Design Institute (Group) Co., Ltd. Shanghai, China \\ Jun Ma \\ School of Municipal and Environmental Engineering, Harbin Institute of Technology, Harbin, Heilongjiang, \\ China \\ Yuzhu Fan, Shuo Zhang \& Minjie Xiao \\ Shanghai Municipal Engineering Design Institute (Group) Co., Ltd. Shanghai, China
}

\begin{abstract}
The Guanjingang water plant has a capacity of $300,000 \mathrm{~m}^{3} / \mathrm{d}$ and is one of the main water plants of Jiaxing City in Zhejiang Province, which is located in the southern suburban area of this city. Its second phase with an augmentation of capacity of $150,000 \mathrm{~m}^{3} / \mathrm{d}$ was put into operation in September, 2012. The raw water for this plant is the surface water that purified by the artificial wetlands and goes through the combined treatment of a biological preprocess, with both conventional and advanced process, to ensure the water quality meets the standard. This paper mainly focuses on the three key problems: the seasonal high ammonia-nitrogen, biological security and $\mathrm{pH}$ control of outlet water. And it aims to optimize and analyze the combined processes including the artificial wetlands, biological pretreatment, sand filtration and advanced treatment with ozone-activated carbon. Subsequently, the new treatment process applied to this practical engineering design is proposed.
\end{abstract}

Keywords: $\mathrm{NH}_{3}-\mathrm{N}$; artificial wetland; sand filtration; ozone-activated carbon; biofiltration

\section{PREFACE}

The raw water of the Guanjinggang water plant comes from the Guanjinggang River, which is located to the south of the plant. The water source is polluted by organic substances and metals, $\mathrm{NH}_{3}-\mathrm{N}, \mathrm{COD}_{\mathrm{Mn}}$, total nitrogen, total phosphorus, dissolved oxygen, iron and manganese all exceed the acceptable limits of class III water according to the "Environment quality standards for surface water" (GB3838-2002). In particular, the seasonal high ammonia-nitrogen in winter is a major problem during the purification process. Figure 1 shows the flow chart of the first phase project layout of the Guanjinggang water plant.

Each step of the treatment process aims to eliminate the targeted pollutants. First, the biological pretreatment aims to degrade the ammonia nitrogen then the intermediate high density sedimentation tank removes turbidity; subsequently, the biological activated carbon advanced treatment eliminates organics; finally, the sand filter ensures that the biosecurity and level of turbidity reach the standard.

\section{KEY ISSUES}

The key issues during the process selection and design for the second phase project of the Guanjinggang water plant are the seasonal high ammonia-nitrogen, biosecurity, $\mathrm{pH}$ control of outlet water and energy saving.

\subsection{Seasonal high ammonia-nitrogen}

The changes of the ammonia nitrogen in the raw water, pretreatment, precipitation, oxidation, carbon filter and sand filter effluent are shown in Figure 2 from beginning $(08 / 2007)$ to winter $(02 / 2008)$ and summer $(07 / 2008)$, which was the early stage of the first phase of the Guanjinggang Water plant.

At the early stages of the first phase project, the ammonia nitrogen concentration in the raw water is generally below $2 \mathrm{mg} / \mathrm{L}$, which means the whole process including comprehensive biological pretreatment-strengthening coagulation and sedimentation-biological activated carbon-advanced filtration with biological-physical-chemical synergism, can meet the standard of outlet water quality. However, after the second half of 2008, the raw water quality changed because the amount of $\mathrm{COD}_{\mathrm{Mn}}$, ammonia nitrogen, total phosphorus, total nitrogen, iron and manganese rose significantly. In particular, the worsening of the pollution caused by ammonia nitrogen and the filler deposition in the biological pretreatment

This is an Open Access article distributed under the terms of the Creative Commons Attribution License 4.0, which permits unrestricted use, distribution, and reproduction in any medium, provided the original work is properly cited. 


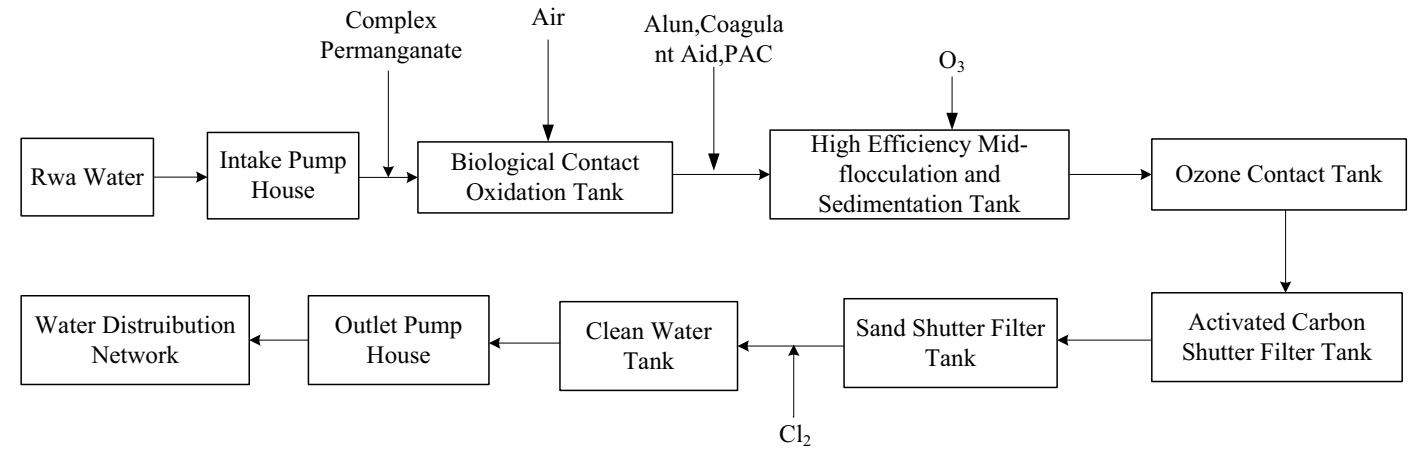

Figure 1. Flow chart of the first phase project layout of the Guanjinggang water plant

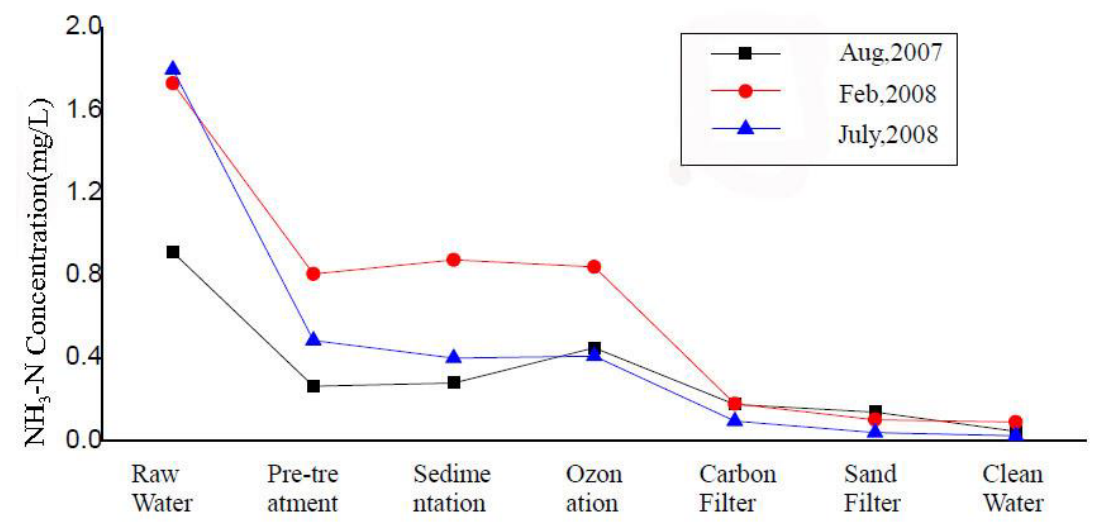

Figure 2. Changes of the ammonia nitrogen concentration during the treatment process

process in winter and the problems regarding aquatic animal control have resulted in a cost increase of the treatment process and higher requirement of daily operation management. Under such circumstances that a high level of ammonia nitrogen in winter has been always one of major difficulties of processing micro polluted water sources for those water plants from central and northern China, the study of and innovative ideas about this process are of considerable academic value and of significance to domestic and foreign waterworks of a similar nature.

\subsection{Biosecurity}

For those water plants adopting the process of biological pretreatment-ozone activated carbon, how to avoid the aquatic organisms and the biofilms attached to active carbon not to penetrate into clean water tanks and the water supply pipe network is very critical for ensuring biological security. The whole process layout in the second phase project should be optimized to prevent a biological leak.

\section{3 pH control of outlet water}

The pollutants in the filter and activated carbon tank are biodegraded by a large number of microorganisms. At the same time, the biological metabolism consumes oxygen and releases $\mathrm{CO}_{2}$. As a result, $\mathrm{PH}$ value of water decreases and, it is very possible that the water can become acidic and it then affects the quality of the treated water and the stability of the water supply network if the alkalinity in water is insufficient. The raw water's $\mathrm{pH}$ value at the Guanjinggang plant is not high, generally around 7.5; therefore, it becomes a critical issue during the process control of the second phase project.

\subsection{Energy saving in the process}

The long process at the Guanjinggang water plant includes biological pretreatment, conventional treatment and advanced treatment, all of which consumes large quantities of water. Therefore, how to control the water loss in each stage and achieve the energy saving throughout the whole process is one of the main tasks for the second phase of the project. 
EMME 2015

Table 1. The ammonia nitrogen removal with the sand filtration process of water plant $\mathrm{S}$ and $\mathrm{K}$

\begin{tabular}{l|l|l|l|l|l}
\hline \multirow{2}{*}{ Date } & Temperature $\left({ }^{\circ} \mathrm{C}\right)$ & $\mathrm{NH}_{3}$-N Concentration $(\mathrm{mg} / \mathrm{L})$ & \multicolumn{4}{l}{} \\
\cline { 3 - 6 } & & K Plant Sand Filter Effluent & Removal & S Plant Sand Filter Effluent & Removal \\
\hline \multirow{3}{*}{ Dec 2009 } & Below 5(2 days) & 0.54 & 1.15 & 0.30 & 0.94 \\
\cline { 2 - 6 } & 6-10(28 days) & 0.56 & 1.11 & 0.38 & 0.76 \\
\cline { 2 - 7 } & Upon 11(1 day) & 0.31 & 1.11 & 0.25 & 0.61 \\
\cline { 2 - 7 } & Average & 0.55 & 1.11 & 0.37 & 0.77 \\
\hline \multirow{5}{*}{ Jan 2010 } & Below 5(8 days) & 0.27 & 1.11 & 0.27 & 0.68 \\
\cline { 2 - 7 } & 6-10(23 days) & 0.25 & 1.17 & 0.16 & 0.78 \\
\cline { 2 - 6 } & Average & 0.26 & & & 0.76 \\
\hline
\end{tabular}

3 AN ANALYSIS OF THE AMMONIA- NITROGEN ELIMINATING PROCESS

One purpose of the second phase project is to reduce as much ammonia nitrogen value as possible in treated water though prolonging the biological treatment process for the removal of ammonia nitrogen in winter when there is a low temperature and/or poor biological activity.

In actual operation, when the water temperature is going down and the ammonia nitrogen value increases quickly, controlling the ammonia nitrogen value of the outlet water is most difficult. However, by increasing the dosage of various medicaments and enhancing the treatment effect of each process, the ammonia nitrogen value in treated water can be controlled to meet the performance assessment criteria.

According to the experiences of similar water purification projects, the main effective ammonia-nitrogen eliminating processes include artificial wetland, biological pretreatment, sand filtration and ozone- activated carbon advanced treatment.

\subsection{Ammonia nitrogen removal with artificial wet- land technology}

Artificial wetland technology as a biological treatment and restoration method has been widely studied in recent years ${ }^{[1-4]}$ and has been used in water resource ecological wetland restoration projects. Zhejiang Province already has the similar project experiences on surface river water resource restoration.

After water has flowed through the artificial wetland, there is a significant improvement in the dissolved oxygen, ammonia nitrogen, total nitrogen, total phosphorus, and $\mathrm{BOD}_{5}$ index. Therefore, the biological treatment extension effect is obvious. The resulting organic removal effect by conventional structures can be effectively improved, especially the noteworthy ammonia nitrogen removal effect in the coagulation and sedimentation and filtration tanks.

\subsection{Ammonia nitrogen removal with the biological pretreatment process}

Generally, the biological pretreatment process is prior to the water purification process. By using the oxyg- enolysis and conversion functions of microorganisms attached to the biological filter, the organic pollutants, ammonia nitrogen, nitrite, iron, manganese and other inorganic pollutants are preliminarily removed, of which the ammonia nitrogen removal is particularly obvious ${ }^{[5]}$. By using the biological pretreatment process, the coagulation-sedimentation performance of raw water can be enhanced. Moreover, the processing load of the conventional and subsequent process can be reduced based on the biological extension effect, and the biodegradable organic substances can be removed. Additionally, the disinfectants and their by-products can be reduced to increase the biological stability of drinking water.

\subsection{Ammonia nitrogen removal with the sand filtra- tion process}

Under the conditions of a sufficient amount of dissolved oxygen and without any disinfection, a certain amount of ammonia nitrogen, iron and manganese ion ${ }^{[6-9]}$ can be removed by sand filtration due to its biological effect. Comparing the effluent water quality from the sand filter of water plant $\mathrm{S}$ (with biological pretreatment) and $\mathrm{K}$ (without biological pretreatment) in winter, the ammonia nitrogen removal effect using the sand filter is significant and the relative detection results are shown in Table 1.

\subsection{Ammonia nitrogen removal with the ozone-activated carbon process}

The ozone-activated carbon process has a particular role in the removal of ammonia nitrogen ${ }^{[10,11]}$, though there was a fluctuation in the beginning operation. The removal effect of ammonia nitrogen by using biological activated carbon in the first phase project of Guanjinggang water plant is shown in Figure 3 and Figure 4. The average effluent ammonia nitrogen concentration is $0.12 \mathrm{mg} / \mathrm{L}$, which is decreased by $76.8 \%$ than that of the inlet water. The removal rate was stable throughout the process. The rebound of the ammonia nitrogen concentration within ozone contact tank during the early operation is probably due to the existence of catalytic oxidation material that promotes the oxidation of organics and further leads to the release of ammonia nitrogen. Once the operation is stable, the 


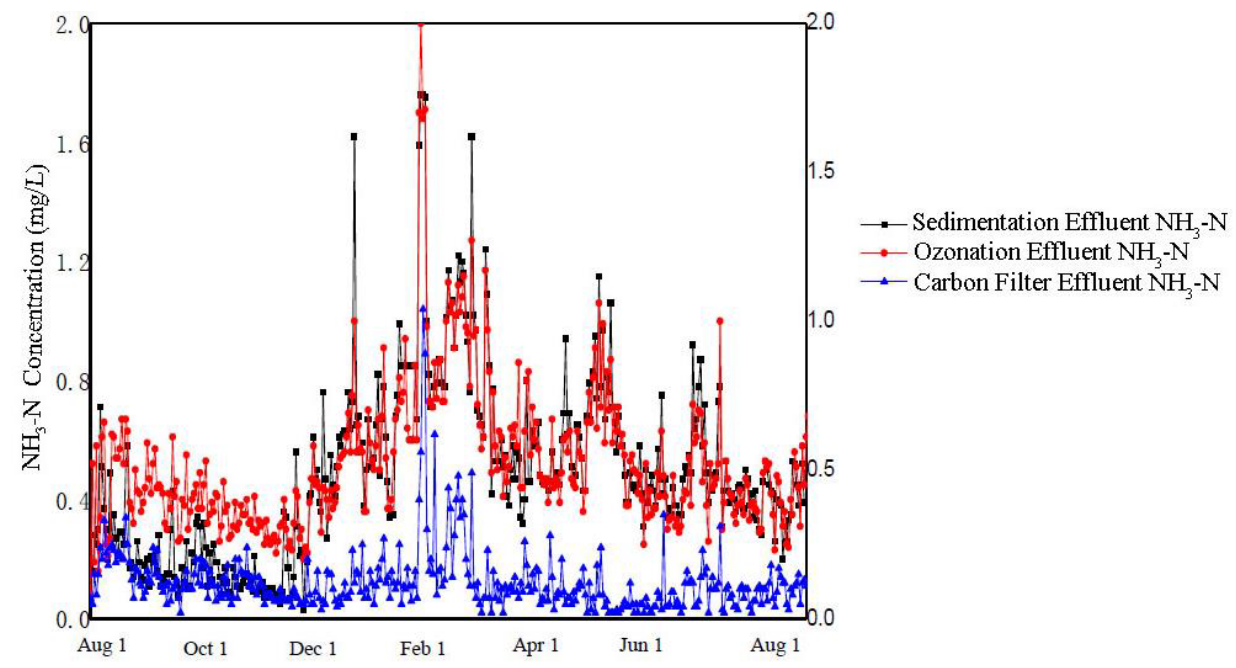

Figure 3. The ammonia nitrogen removal effect with biological activated carbon in the Guanjinggang water plant

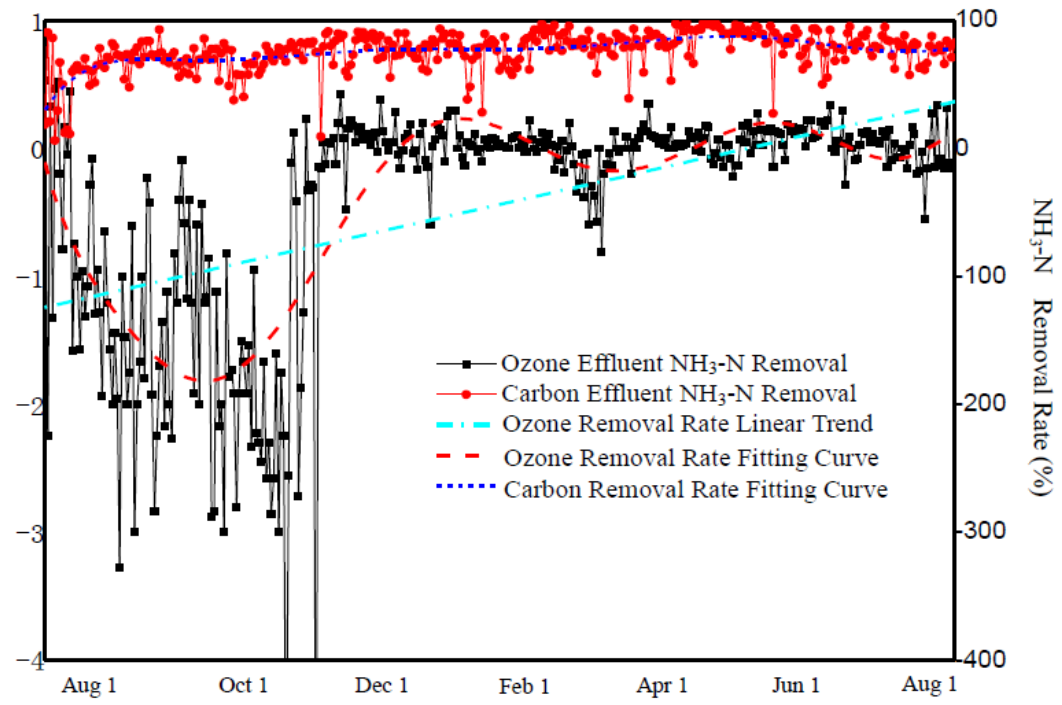

Figure 4. The ammonia nitrogen removal rate with biological activated carbon in the Guanjinggang water plant

ozone contact oxidation has little impact on the effluent ammonia nitrogen concentration. The effluent ammonia nitrogen removal rate is $63.2 \%$ when using the ozone-biological activated carbon combined process. After flowing through the filter, the effluent ammonia nitrogen concentration can be reduced to $0.5 \mathrm{mg} / \mathrm{L}$ or less than that.

\section{SOLUTION ANALYSES}

\subsection{Combined processes}

The process of the second phase project in the Guan- jinggang water plant should be altered to adapt to changes in the raw water quality. The artificial wetland purification engineering should be carried out at the water resource, and the process of the first phase project should conduct further optimization. In the second phase project, the effluent water from the ecological wetland is used as raw water, and the biofiltration pool is added to the rear of the precipitation pool to remove the ammonia nitrogen organics by using its curing effect. The new process of the second phase project can be simply described as pre- oxidation-coagulating-sedimentation-biological filtrationozone-biological activated carbon-sand filtration. 
4.2 Control of effluent ammonia nitrogen and biosecurity

In the second phase project, the ozone-biological activated carbon is set up between the two-stage filtration behind the precipitation pool. The combined multistage reactor for the removal of ammonia nitrogen, organic matter, $\mathrm{Fe}$ and $\mathrm{Mn}$ and the turbidity control of effluent water ensures the water quality and reduces the influence of temperature change on the efficient removal of ammonia nitrogen. The combined process provides both enhancement and innovation.

By the aid of the cheap biological effect of the ecological wetland pretreatment, ammonia nitrogen and the hydrophilic organic matter that with a molecular weight which is less than $3 \mathrm{kD}$ can be completely removed to a certain extent. Furthermore, suspended matter, colloidal organic with a molecular weight more than $10 \mathrm{kD}$ and probable colloidal organic with a molecular weight of $1-10 \mathrm{kD}$ can all be removed by using the chemical pre-oxidation of the advection sedimentation tank. By adding filter aid to the biological filtration pool, the organic matter, ammonia nitrogen, iron and manganese can be completely removed to a certain extent. Then the hydrophilic organic matters with a molecular weight of $1-10 \mathrm{kD}$ can be oxidized into small molecules, which can be easily adsorbed to the activated carbon by the use of ozone. The sand filtration pool with filter aid added is the last barrier where the activated carbon biomembrane, the suspended matter generated by ozone oxidation, the biomembrane generated in the sand filter, and the residual small molecules can be trapped. The new process can control the water turbidity and reduce the organic matter content, thus ensuring effluent biosecurity. In the winter, after the removal of most of the organic matter, the residual ammonia nitrogen is formed into chloramines by adding chlorine; this effectively prolongs the disinfection time and ensures the security of water quality and the likelihood of the effluent water ammonia nitrogen reaching the desired standard.

\section{3 pH control of effluent water}

The raw water's $\mathrm{pH}$ value at the Guanjinggang water plant is not high. Because there are two filter pools and an activated carbon adsorption tank in the second phase project, the alkalinity consumption of raw water is greater than that of the conventional process. Therefore, stable effluent water is one of the most important goals of the whole operation management process.

In the actual operation, multi-point adding alkali is adopted. The biological filter and activated carbon adsorption tank have certain regulation abilities because of their biological function. The operation effect can be ensured by controlling the $\mathrm{pH}$ value of the inlet water. Therefore, the two pools will either need a small amount of alkali or not. The sand filtration pool at the end of the process has a bearing on the effluent biosecurity, turbidity and stability control. Hence plenty of alkali should be added to the sand filtration pool according to the production requirements.

\section{ENGINEERING DESIGN OF THE SECOND PHASE PROJECT}

The process in the second phase project of the Guanjinggang water plant combines the reinforced conventional treatment with the advanced treatment. It includes mechanical reaction, flocculation with folded plates, sedimentation, the biofiltration pool, ozone, biological activated carbon and the sand filtration pool. The belt press filter dewatering process is also used to treat sludge. The process flow chart is shown in Figure 5.

\subsection{The mechanical mixing-folded plates flocculation and sedimentation tank with lamination of clear water tank}

A sedimentation tank with lamination is constructed in the second phase project, the upper part of which has a mechanical mixing flocculation and sedimentation pool and the lower part has a clear water pool, the capacity of which is $150,000 \mathrm{~m}^{3} / \mathrm{d}$. It includes two mechanical mixing tanks with a mixing time of $30 \mathrm{~s}$ and a flocculation with a concrete folded plate that has a reaction time of about $20 \mathrm{~min}$ and sedimentation pool. The residence time of the advection sedimentation tank is about $104 \mathrm{~min}$. The outlet channel of the sedimentation tank is broadened and has aeration disks and elastic fillers installed to add oxygen to the water. Subsequently, the effluent water accesses the inlet channel of the biofiltration pool.

\subsection{Biofiltration pool}

In the second phase project, a biofiltration pool is constructed with a capacity of $150,000 \mathrm{~m}^{3} / \mathrm{d}$. It is divided into eight parts using a double row layout. The filtration area of each part is $105 \mathrm{~m}^{2}$ and the designed filtration rate is $7.8 \mathrm{~m} / \mathrm{h}$. Uniform quartz sand is used as a filtration medium with the effective particle diameter of $0.95 \mathrm{~mm}$, the non-uniform coefficient $\mathrm{K}_{80}$ is less than 1.4 with a thickness of $1.5 \mathrm{~m}$. The particle diameter of quartz sand located at the support layer is $2.0-4.0 \mathrm{~mm}$ and the thickness of the support layer is $0.10 \mathrm{~m}$. The biological filtration cycle is $24 \mathrm{~h}$. The way it backwashes acts as a gas-water recoil and sweeps the pool's surface. The prefabricated filtration plate and long-handled filtration head are used for the distribution of water and gas.

Two mixing pools are set up at each end of the filtration pool to the dosage of the filter aid. Each mixing pool with a residence time of 30 s has a rapid mixer and an annular tube for dosing the alum. 


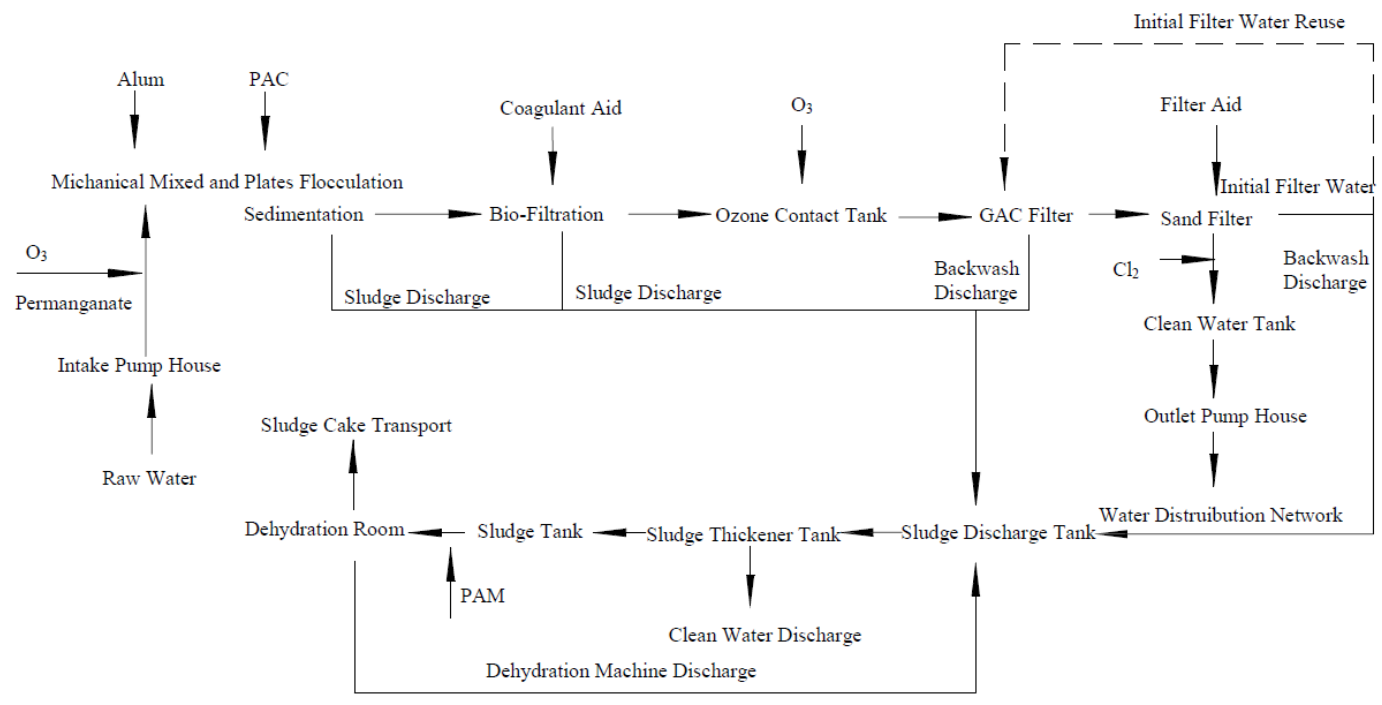

Figure 5. Process flow chart of the second phase project of the Guanjinggang water plant

\subsection{Mid-pumping station, ozone contact tank and ozone generator workshop}

The mid-pumping station and ozone contact tank are constructed together. The mid-pumping station has four submersible mixed-flow pumps with variable frequencies, of which three are used and one is stand-by. The submersible mixed-flow pumps are installed in the form of an open shaft. The outlet of the single pump is designed as a series of small compartments, and it is connected to the ozone contact tank via the overflow weir effluent channel. The ozone contact tank with a contact time of $17 \mathrm{~min}$ is divided into two lattices. After experiencing a three-stage reaction, the water falls into the activated carbon filtration pool. The designed maximum filling quantity of the ozone generator workshop is $4 \mathrm{mg} / \mathrm{L}$, wherein the former part's ozone quantity is $0.5-1 \mathrm{mg} / \mathrm{L}$, which is added by the mixer to the outlet pipeline in the water intake pump house, and the latter is $2.5-3 \mathrm{mg} / \mathrm{L}$, which is added by the ozone aeration disc feeding.

\subsection{Activated carbon/sand filtration pool}

A combined filtration pool is constructed using a double row arrangement with a capacity of $150,000 \mathrm{~m}^{3} / \mathrm{d}$. The upward-flow activated carbon filtration pool is located in the north and the sand filtration pool in the south. Both of them are divided into nine lattices sharing the intermediate pipe gallery.

(1) Upward-flow activated carbon filtration pool

The outlet water of the ozone contact tank flows into the upward-flow activated carbon filtration pool. After supplying water and air via the lower part, the water flows through the activated carbon adsorption layer from the bottom to the top, and then flows out from the upper finger groove. Then the water flows via channels into the coagulant aids' mixing zone.
After a rapid mixing for 20 s, the water flows via the communicating pipe into the inlet channel of the sand filtration pool.

The filtration rate of the activated carbon pool is $11.6 \mathrm{~m} / \mathrm{h}$. The residence time and thickness of the carbon layer are respectively $13 \mathrm{~min}$ and $2.5 \mathrm{~m}$. The thickness of the gravel bearing layer is $0.45 \mathrm{~m}$.

(2) Sand filtration pool

The filtration rate of the V-typed sand filter is $7 \mathrm{~m} / \mathrm{h}$. The filtration layers from top to bottom include a quartz sand layer with a particle diameter of $0.85 \mathrm{~mm}$, a non-uniform coefficient of 1.4 and a thickness of $1.2 \mathrm{~m}$, and a supporting layer with a particle diameter of $2.0-4.0 \mathrm{~mm}$ with thickness of $0.10 \mathrm{~m}$.

\section{CONCLUSIONS}

The key issues for the process selection of the second phase project of the Guanjinggang water plant are seasonal high ammonia-nitrogen, biosecurity and $\mathrm{pH}$ control of outlet water. The project uses the outlet water treated by ecological wetland as raw water. The new process of the project can be simply described as preoxidation-coagulating-sedimentation-biological filtration-ozone-biological activated carbon-sand filtration. The new process can control the water turbidity and reduce the organic matter content, thus ensuring effluent biosecurity. Multi-point adding alkali is adopted in the actual operation. The $\mathrm{pH}$ value control of the inlet water of the biological filtration pool and activated carbon adsorption tank can ensure the operation effect. Therefore, a small amount of alkali can either be added into the inlet water of the two pools or not. It is suggested that plenty of alkali should be added to the sand filtration pool according to the production requirements.

Based on the analysis on the process layout, the 
second phase project of Guanjinggang water plant can be regarded as a "long process". The overhead sedimentation tank superimposes with other structures, where the deep pool is adopted. The mid-pumping station is arranged, the pool type layout is optimized and a high efficiency lift pump is used to reduce the water loss and implement energy savings.

\section{ACKNOWLEDGEMENT}

All the authors extend their sincere thanks to Mr. Zha Renguang and Mr. Zhu Haitao, and they also thanks for the assistance from Jiaxing Jiayuan Water Supply and Drainage Company.

The authors would like to acknowledge financial supported by the key Special Program on the S\&T for the Pollution Control and Treatment of Water Bodies (No.2012ZX07403-003) and Shanghai Municipal Engineering Design Institute (Group) CO., LTD (K2015K039).

\section{REFERENCES}

[1] Zheng, Y.C., Wang, X.C., Xiong, J.Q., Liu, Y.J., \& Zhao, Y.Q. 2014. Hybrid constructed wetlands for highly polluted river water treatment and comparison of surface- and subsurface-flow cells. J. Environ. Sci. (4):749-756

[2] Cui, E, Zhou, Q., Wang, Y., \& Zhao, Y.Q. Application of constructed wetland for urban lake water purification Trial of Xing-qing Lake in Xi'an city, China. J. Environ. Sci. Health 46(7):795-799.
[3] Dong, H.Y., Qiang, Z.M., Li, T.G., Jin, H., \& Chen, W.D. Effect of artificial aeration on the performance of vertical-flow constructed wetland treating heavily polluted river water. J. Environ. Sci. 24(4): 596-601.

[4] Yang, X., Yu, S.L., Zhao, Y., Yan, X.J., Xiu, C.H., \& Wang, D.G. Efficiency and mechanism of pretreatment on water supply in reservoirs of Yellow River by subsurface constructed wetlands. J. Harbin. Ins. Tech 16(5):652-655.

[5] Xie, S.G., Tang, X.Y., Wu, W.Z., Wen, D.H., \& Wang, Z.S. Biological pretreatment of Yellow River water. $J$. Environ. Sci. 17(4):557-561

[6] Sun,J., Tian, Q., Li, F., Wang, F.R., \& Yang, B., 2013. Enhancing Phosphorous Recovery in a Novel Biofilter System. J. Donghua. Univ. 30(2):132-136

[7] Levlin E, Lowen M, \& Stark K, et al. Effects of Phosphorus Recovery Requirements on Swedish Sludge Management. J. Water Sci. Tech. 46 (4/5): 435-440.

[8] Marti N, Bouzas A, \& Seco A, et al. Struvite Precipitation Assessment in Anaerobic Digestion Processes $J$ Chem. Engi. 141 (1/2/3): 67-74.

[9] Le, C. K. S., Valsam, J. E., \& Hobbs, P., et al. Phosphorus Recovery from Wastewater by Struvite Crystallization: a Review. J. Critical Reviews in Envi. Sci. Tech 39(6):433-477.

[10]Pan, C.G., Ye, L.Q., Wang, J.H., Bao, L.X., \& Que, Y.S Pretreatment of Cylindrical Coconut Activated Carbon and Performance as Catalyst Support. Chem. Res. Chin. Univ. 29(5):941-946.

[11]Lu, S.M., Chen, J.L., \& Li, F. 2013. Investigation on the Key Factors and the Solution for $\mathrm{pH}$ Value Decrease in Carbon Filter in O3-BAC Process. J. Chem. Engi. (8):914-919. 